\title{
Cytoarchitecture of the cerebellum in fluoride and aluminium toxicity
}

\author{
Akinrinade I. D. ${ }^{1}$, Ogundele O. M. ${ }^{2}$, Memudu A. E. ${ }^{1}$ and Obia S. ${ }^{1}$ \\ ${ }^{1}$ Department of Anatomy, Bingham University, Karu, Nasarawa State, Nigeria. \\ ${ }^{2}$ Department of Anatomy and Cell Biology, Afe Babalola University, Ado Ekiti, Nigeria.
}

Accepted 4 June, 2013

\begin{abstract}
Drinking water is a major source of fluoride and aluminium intake and these substances are known to cross the blood-brain barrier and alter the structure and function of neural tissues. One concern that has not been fully investigated is the link between fluoride, aluminium and their effects on the central nervous system. Twenty female Wistar rats were used for this investigation. Fifteen which served as the treatment group were given sodium fluoride, aluminium fluoride and their combination. The control was given distilled water for 21 days. The cerebellum was excised and histological investigations were carried out using routine Haematoxylin and Eosin, Periodic-acid Schiff and Cresyl violet stains. Results revealed appearance of vacuolar spaces, cellular fragmentation and ghost-like appearance of neuronal cells of the treatment group, while the cells of the control group appeared intact with regular cell morphology and intact cellular integrity.
\end{abstract}

Key words: Sodium fluoride, aluminium chloride, cerebellum, neurotoxicity.

\section{INTRODUCTION}

Fluoride is the monovalent anion derived from the element fluorine and it is present in many salts, including sodium fluoride and aluminium fluoride. When these salts are dissolved in water, the free fluoride ions are released (Aigueperse et al., 2005). Fluoride salts or other compounds that release fluoride ion may be added to drinking water to prevent dental caries (Bassin et al., 2006). Fluoride releasing compounds are also added for this purpose to a wide variety of dental products including toothpastes and mouthwashes (Levy and GuhaChowdhury, 1999). The public is exposed to fluoride ion by drinking fluoridated water and by using fluoride-containing dental products and treatments. Exposure may also occur through naturally present fluoride in foods and beverages, and in some cases by inhalation of fluoride compounds in the air (Aigueperse et al., 2005).

Individual and population exposures to fluoride vary considerably and depend on the high variability in the levels of fluoride found in tap (be it natural or the result of intentional fluoridation of drinking water) and mineral waters, and on individual dietary and oral hygiene habits and practices (Aigueperse et al., 2005). This shows that there is a narrow margin between the recommended therapeutic intake of fluoride (1 ppm) and the upper limits of exposure (Varner, 1998). Therefore, consistent monitoring of the exposure of humans to fluoride from all sources and an evaluation of new scientific developments on its toxicity are required as it has been reported that fluoride affects a wide range of organs in the body including the brain, thyroid, testicular function, ovary, etc. thereby affecting the body metabolism such as reduction in nicotinic acetylcholine receptors; reduction in lipid content; impaired anti-oxidant defense systems; damage to the hippocampus; damage to the purkinje cells; increased uptake of aluminium; formation of beta-amyloid plaques (the classic brain abnormality in Alzheimer's disease); exacerbation of lesions induced by iodine deficiency; and accumulation of fluoride in the pineal gland (Varner, 
1998).

Aluminium is the third most abundant metal on earth and reports have revealed that it is a major neurotoxin and disrupter of neurological function (Blaylock, 2011). It has also been established that aluminium is not essential to human metabolism at any concentration (Exley and House, 2011). Humans are exposed to aluminium by a number of routes, including foods, industrial exposures, drinking water, pharmaceuticals and vaccines (Blaylock, 2011) and in experimental animals. Aluminium was reported to cause progressive neurological impairment of learning and memory performance as well as altered motor function (Chinoy et al., 1999).

While absorption from the gut is quite poor, aluminium that is introduced via parenteral fluids and vaccines is completely absorbed and distributed throughout the body (Tomljenovic and Shaw, 2011).

It is of significant concern that low-levels of environmental aluminium are sufficient to induce neurotoxic outcomes (Campbell et al., 2004). Also, experimental evidence shows that aluminium preferentially accumulates in the mitochondria and cell nucleus, which makes this metal very resistant to removal (Kruck et al., 2004). Therefore, the long-term intracellular persistence of aluminium is likely to increase its toxic effects. The difficulty of removing brain intracellular aluminium will lead to its progressive accumulation over a lifetime, eventually reaching a neurotoxic threshold sufficient to trigger neurodegenerative disease processes (Walton and Wang, 2009).

This study therefore is designed to investigate the neurotoxic potentials of fluoride and aluminium on the cerebellum by histological and quantitative parameters using sodium fluoride and aluminium chloride.

\section{MATERIALS AND METHODS}

\section{Animals}

Twenty Wistar Albino rats weighing between 200 and $250 \mathrm{~g}$ were used for this study. The rats were purchased from Nigerian Institute of Vertinary Research (NIVR) located in Jos, Plateau State. They were housed in well ventilated stainless-steel cages at room temperature $\left(24 \pm 2^{\circ} \mathrm{C}\right)$ in hygienic condition under natural light and dark schedule and were fed on standard laboratory diet. The animals were fed with standard pelletized feed and water was provided ad libitum. Animals were handled in accordance with the approval of ethics regulation at Bingham University throughout the period of study.

\section{Chemicals}

Sodium fluoride of $99 \%$ purity and aluminium chloride of $97 \%$ purity were obtained from SUNLAB Chemicals Ltd, Jos, Plateau State.

\section{Administration}

The doses administered were prepared from the $L_{50}$ values of each compound (WHO, 1997). The doses administered for sodium fluoride is $10 \mathrm{mg} / \mathrm{kg}$ body weight and aluminium chloride is 200 $\mathrm{mg} / \mathrm{kg}$ body weight. Such that $20 \%$ of the $\mathrm{LD}_{50}$ value was used for this study (Chinoy et al., 1996).

\section{Animal grouping and treatment}

The rats were randomly divided into four groups of five (5) animals in each group and treated for 21 days as follows:

Group 1: Received sodium fluoride (10 mg/kg bw) by gavage.

Group 2: Received aluminium chloride (200 mg/kg bw) by gavage.

Group 3: Received sodium fluoride (5 $\mathrm{mg} / \mathrm{Kg} \mathrm{bw}$ ) and aluminium chloride (100 mg/kg bw).

Group 4: Received water $(10 \mathrm{ml} / \mathrm{kg})$ also by gavage.

After twenty one days of administration, all the animals were sacrificed by cervical dislocation and their cerebellum were excised and fixed in $10 \%$ formol calcium which were later processed for histological studies.

\section{RESULTS}

Histological changes in the cerebellum of Wistar rats preexposed to toxic dose of sodium fluoride are shown in Figure 1. Group 1 (NaF) showed enlarged cell bodies and degeneration of cellular architecture as well as abnormal appearance of cells (Figure 1A, B and C) when compared with the control group (Figure 1D and E) that revealed well arranged cell bodies without any distortion with nuclei staining blue and cytoplasm staining pink.

Histological changes in the cerebellum of Wistar rats pre-exposed to toxic dose of aluminium chloride are shown in Figure 2. Group $2\left(\mathrm{AlCl}_{3}\right)$ showed some slight form of cell degeneration (Figure $2 \mathrm{~A}$ and $\mathrm{B}$ ) and less staining intensity of the cell bodies (Figure $2 \mathrm{C}$ ) as a result of treatment with aluminium chloride $\left(\mathrm{AlCl}_{3}\right)$ when compared with the control group (Figure 2D and E).

Histological changes in the cerebellum of Wistar rats pre-exposed to sodium fluoride and aluminium chloride are shown in Figure 3. Group $3\left(\mathrm{NaF}+\mathrm{AlCl}_{3}\right)$ showed high degree of cell degeneration when compared with the treated groups and the control. The degenerated cells were also marked with appearance of vacuolar spaces found distributed among the cells, indicating the combined effects of $\mathrm{NaF}$ and $\mathrm{AlCl}_{3}$. There was also presence of ghost-like appearance of cell bodies (Figure 3C).

\section{DISCUSSION}

This study confirms the neurotoxicity of fluoride and aluminium in the cerebellum as evident in the appearance of pyknotic nuclei, appearance of vacuolar spaces as an indication of cellular degeneration and ghost like appearance of cells in the treatment groups.

The appearance of enlarged cell bodies in Group 1 provides evidence for the excitotoxic effects of $\mathrm{NaF}$. Another connection between glutamate excitotoxicity and fluoride toxicity is related to inhibition of brain energy production (Blaylock and Ridgeland, 2004). Several studies 

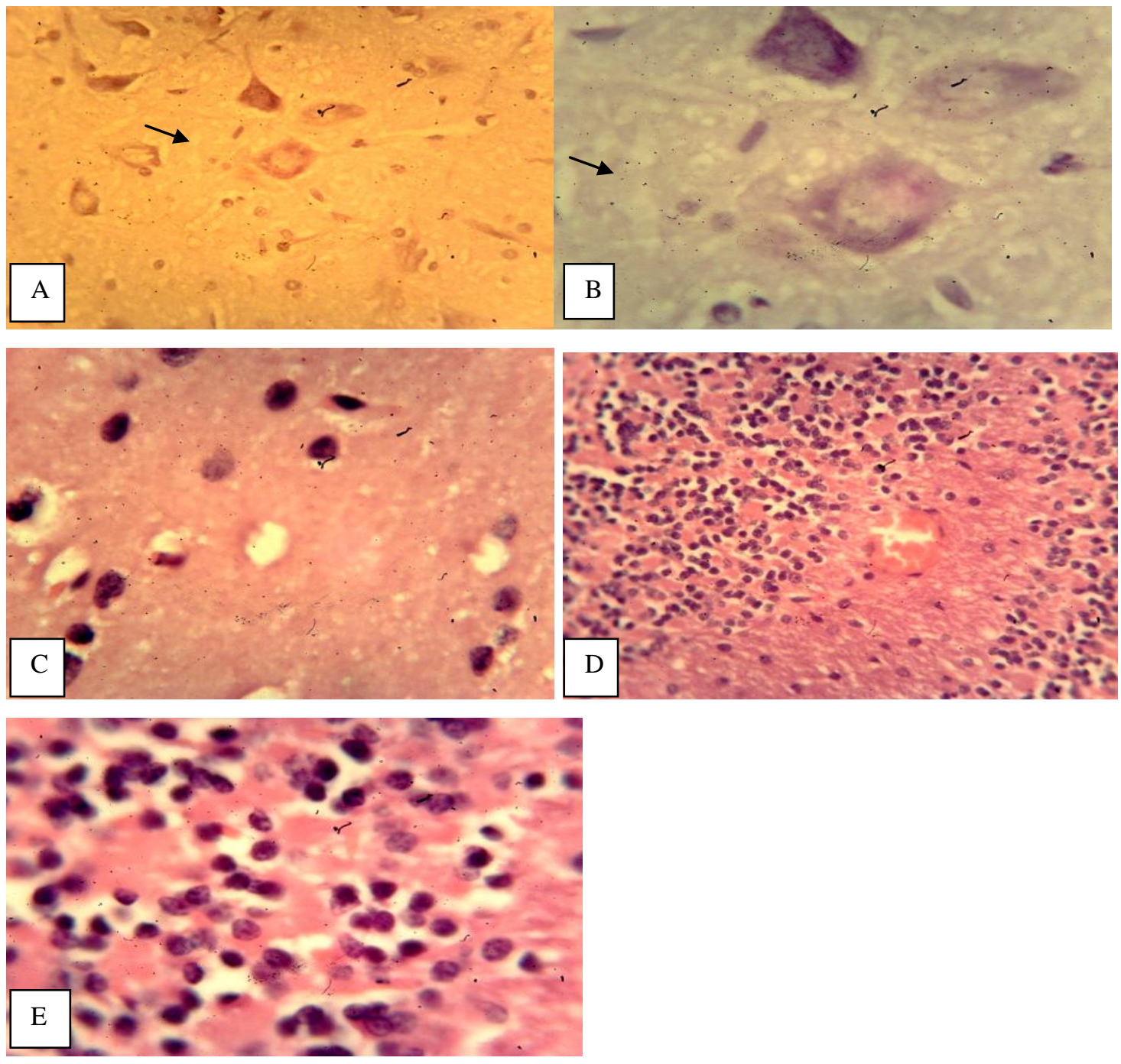

Figure 1. Group $1(\mathrm{NaF})$ : Ultra-structural images showing morphology of different aspect of the cerebellum in $\mathrm{NaF}$ treated and control rats. Arrows showing enlarged cell bodies are shown in $\mathrm{A}(400 \mathrm{x})$ and $\mathrm{B}(1000 \mathrm{x})$ as well as less staining intensity of the nissl bodies. C (1000x) shows appearance of cell degeneration and even empty cell bodies as well as pyknotic nuclei. D and E (control groups: 400 and 1000x, respectively) show normal cell morphology and deep staining intensity of the nissl granules. Cresyl violet stain (A and B), H\&E stain (C, D and E) were used.

have shown that anything that suppresses neuronal energy production, especially mitochondrial energy production, greatly enhances excitotoxic sensitivity (Nicholls and Budd, 1998; Beal et al., 1993; Henneberry, 1989). In fact, it has been reported that when neuronal energy production is low, even physiological levels of excitotoxins such as glutamate can trigger excitotoxicity (Gibson et al., 1999). Fluoride is also known to inhibit cellular energy producing enzymes, including mitochondrial electron transport enzymes (Blaylock and Ridgeland, 2004). It does this both directly, as in the case of glycolytic and Kreb's cycle enzymes (Dousset et al., 1987), and indirectly, as in the case of the mitochondrial enzymes by the effect of peroxynitrite (Ebadi and Sharma, 2003).

The clinical importance of neuronal energy suppression by fluoride lies in the fact that mitochondrial energy suppression is intimately connected as an early event to neurodegenerative diseases such as Alzheimer's dementia and Parkinson's disease (Meltzer et al., 1996; Schapira et al., 1998; Gibson et al., 1999). Since fluoride can inhibit these enzymes, even in low concentrations, there is an increased likelihood that excitotoxicity plays a significant role in this process (Blaylock and Ridgeland, 2004).

In addition, it has been reported that fluoride is said to enhance aluminium absorption from the gastrointestinal mucosa and across the blood-brain barrier (Blaylock and Ridgeland, 2004); also, fluoride is said to readily form a chemical complex with aluminium, which is toxic to neurons such that at low concentrations, they can act as activator of G-proteins in the cell membrane to activate 

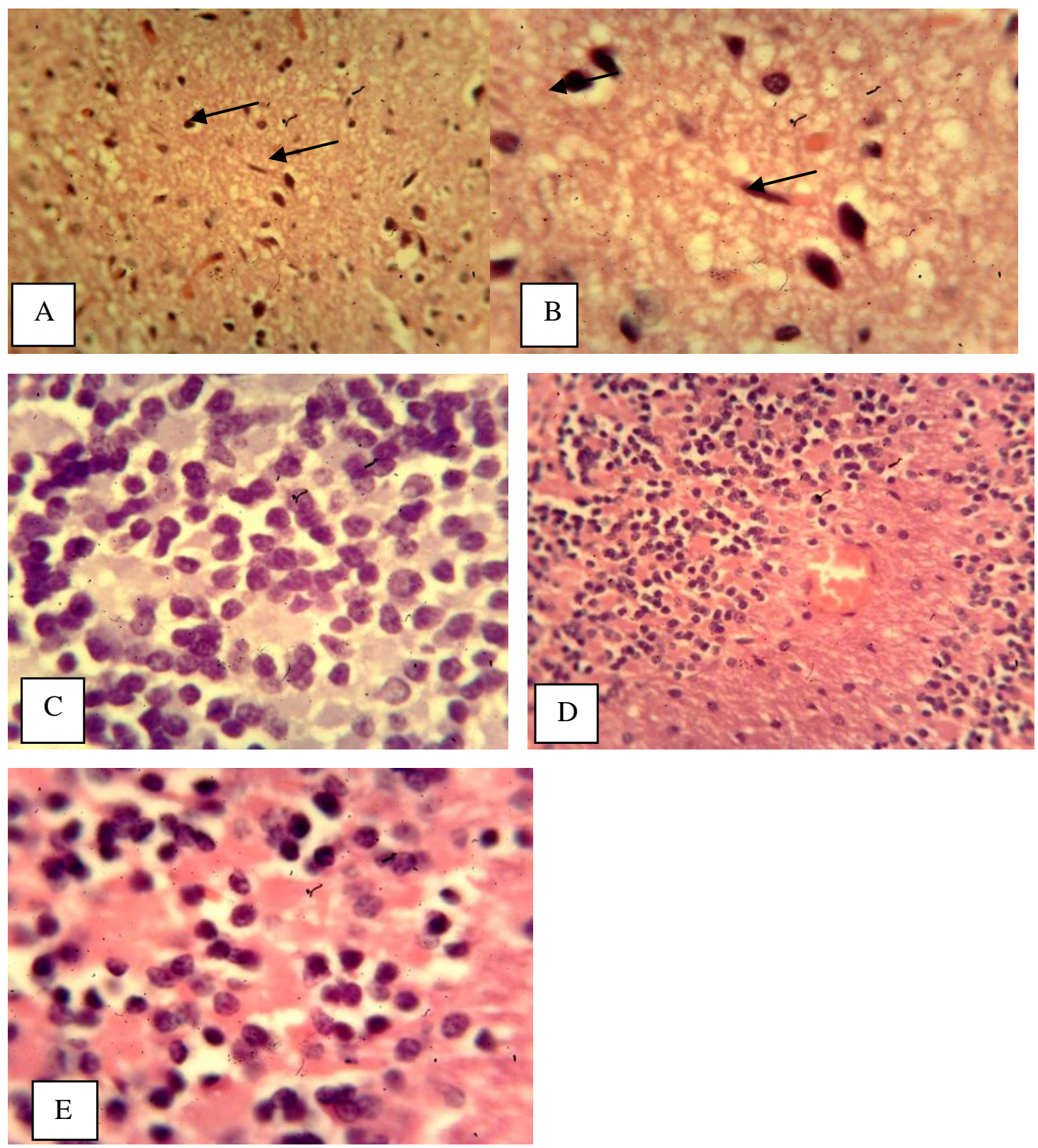

Figure 2. Group $2\left(\mathrm{AlCl}_{3}\right)$ : Ultra-structural images showing morphology of different aspects of the cerebellum in $\mathrm{AlCl}_{3}$ treated and control rats. Arrows in $\mathrm{A}(400 \mathrm{x})$ and $\mathrm{B}(1000 \mathrm{x})$ show a gradual process of neuronal degeneration occurring in the treatment group $\left(\mathrm{AlCl}_{3}\right)$ with slight appearance of vacuolar spaces in their cell bodies. C (1000x) reveals less staining intensity when compared with the control group in $E(1000 x)$. D (400x) and $E(1000 x)$ reveal intact cell morphology and integrity.

the $2^{\text {nd }}$ messenger system in order to activate excitatory receptors especially glutamate thereby leading to excitotoxicity through a positive feedback mechanism (Blaylock and Ridgeland, 2004).

The aluminium-fluoride complex has been shown to produce neuronal degeneration in the CA1 and CA-4 areas of the hippocampus when given to animals as 0.5 ppm in drinking water (Varner et al., 1998) and it is evident in the histological sections of treatment Group 3.

\section{Conclusion}

Fluoride exhibits neurotoxic effects histomorphologically and excitoxicity is the proposed pathway for this neuronal degeneration as evident in Group 1 treated with $10 \mathrm{mg} / \mathrm{kg}$ $\mathrm{NaF}$. Degeneration of neuronal cells shown in Group 2 agrees with the work of Matrac et al. (2010) validating neurodegerative potentials of aluminium in the cerebellum. There is therefore need for extensive research in 

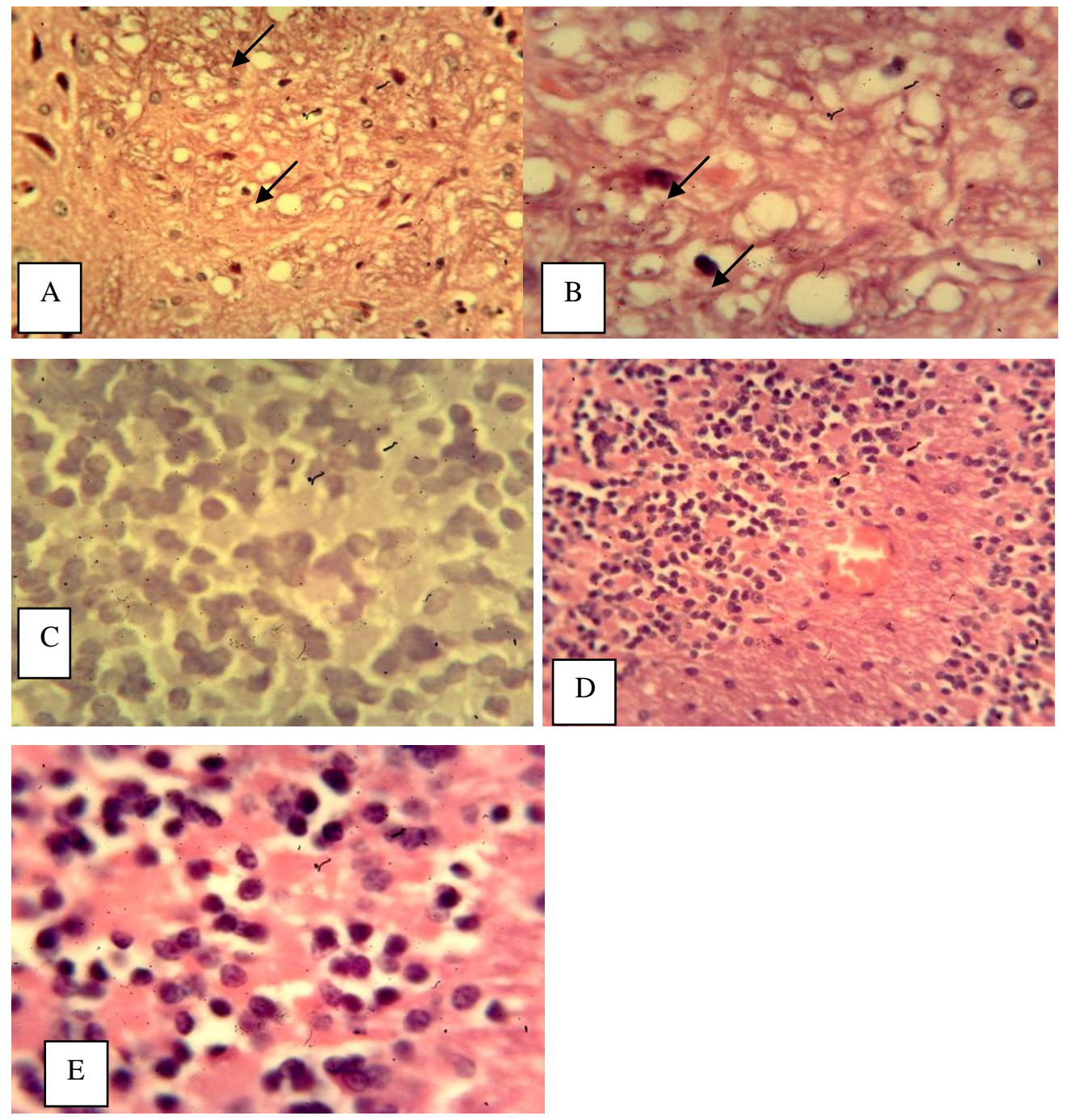

Figure 3. Group $3\left(\mathrm{NaF}+\mathrm{AlCl}_{3}\right)$ : Ultra-structural images showing morphology of different aspects of the cerebellum in $\mathrm{NaF}+\mathrm{AlCl}_{3}$ treated and control rats. $\mathrm{A}(400 \mathrm{x})$ and $\mathrm{B}(1000 \mathrm{x})$ reveal severe neuronal degeneration along with membrane distortion occurring in the treatment group $(\mathrm{NaF}+$ $\mathrm{AlCl}_{3}$ ) when compared with the control (D (400x) and $\left.E(1000 x)\right)$. C (1000x) also reveals presence of ghost-like appearance of neuronal cells in the treated rats. Stains used are H\&E (A, D and E), cresyl violet (Figure $B$ ) and PAS (C).

amelioration of this fluoride induced toxicity of the cerebellum.

\section{ACKNOWLEDGEMENTS}

We thank Ajonijebu, D. C. and Omoaghe, O. A. of the department of Physiology, Afe Babalola University, AdoEkiti, Nigeria for their efforts towards editing the publication. Also, we thank Madukwe, J. of National Hospital, Nigeria for assisting in the histological analysis.

\section{REFERENCES}

Aigueperse J, Mollard P, Devilliers D, Chemla M, Faron R, Romano R, Cuer J (2005). Fluorine Compounds, Inorganic, Ullmann's Encyclopedia of Industrial Chemistry, Weinheim: Wiley-VCH, p. 307.
Bassin E, Wypij D, Davis R, Mittleman M (2006). Age-specific fluoride exposure in drinking water and osteosarcoma (United States). Cancer Causes Control, 7:421-428.

Beal MF, Hyman BT, Koroshetz W (1993). Do defects in mitochondrial energy metabolism underlie the pathology of neurodegenerative diseases? Trends Neurosci, 16:125-131.

Blaylock RL, Ridgeland MS (2004). Excitotoxicity: A Possible Central Mechanism in Fluoride Neurotoxicity. Fluoride; Res. Rep. 37(4):264277.

Blaylock RL (2011). Aluminium induced immunoexcitotoxicity in neurodevelopmental and brain, spinal cord and sciatic nerve of rats treated with sodium fluoride. J. Med. Allied Sci. 1(1):30-35.

Campbell A, Becaria A, Lahiri DK, Sharman K, Bondy SC (2004). Chronic exposure to aluminum in drinking water increases inflammatory parameters selectively in the brain. J. Neurosci. Res. 75(4):565-572.

Chinoy NJ, Bhattacharya S (1996). Effect of single dose of Aluminium Chloride on some reproductive organs and fertility in male mice. Indian. J. Environ. Toxicol. 6:10-13. 
Chinoy NJ, Trupti PN (1999). Reversible toxicity of fluoride and aluminium in the liver and gastrocnemius muscle of female mice. Fluoride 32(4):215-229.

Dousset JC, Rioufol C, Philibert C, Bourbon P (1987). Effects of inhaled $\mathrm{HF}$ on cholesterol, carbohydrate and tricarboxylic acid metabolism in guineapigs. Fluoride 20:137-141.

Ebadi J, Sharma SK (2003). Peroxynitrite and mitochondrial dysfunction in pathogenesis of Parkinson's disease. Antoxid Redox Signal, 5:319335.

Exley C, House E (2011). Aluminium in the human brain. Monatsh. Chem, 142:357-363.

Gibson GE, Park LC, Zhang H, Sorbi S, Calingasan NY (1999). Oxidative stress and a key metabolic enzyme in Alzheimer brains, cultured cells, and an animal model of chronic oxidative deficits. Ann NY Acad. Sci. 893:79-94.

Henneberry RC (1989). The role of neuronal energy in neurotoxicity of excitatory amino acids. Neurobiol Aging, 10:611-613.

Kruck TP, Cui JG, Percy ME, Lukiw WJ (2004). Molecular shuttle chelation: the use of ascorbate, desferrioxamine and feralex-G in combination to remove nuclear bound aluminium. Cell Mol. Neurobiol. 24(3):443-459.

Levy SM, Guha-Chowdhury N (1999). Total fluoride intake and implications for dietary fluoride supplementation. J. Pub. Health Dent. 59:211-223.

Matrac L, Podgorac J, Sekulic S (2010). Evaluation of the neurotoxic effect of aluminium on the Wistar rats. Arch. Biol. Sci., Belgrade. 62(3):585-588.
Meltzer CC, Zubieta JK, Brandt J, Tune LE, Mayberg HS, Frost JJ (1996). Regional hypometabolism in Alzheimer's disease as measured by positron emission tomography after correction for effects of partial volume averaging. Neurobiol. 47:452-461.

Nicholls DG, Budd SL (1998). Mitochondia and neuronal glutamate excitotoxicity. Biochem Biophys Acta. 1366:97-112.

Schapira AH, Gu M, Taaman JW, Tabrizi SJ, Seaton T, Cleeter M (1998). Mitochondria in the etiology and pathogenesis of Parkinson's disease. Ann. Neurol. 44(1):S89-S98.

Tomljenovic L, Shaw CA (2011). Aluminium vaccine adjuvants: Are they safe? Curr. Med. Chem. 18:2630-2637.

Varner JA, Jensen KF, Horvath W, Isaacson RL (1998). Chronic administration of aluminium-fluoride or sodium-fluoride to rats in drinking water: alterations in neuronal and cerebrovascular integrity. Brain Res.784(1-2):284-298.

Walton JR, Wang MX (2009). APP expression, distribution and accumulation are altered by aluminium in rodent model for alzheimer's disease. J. Inorg. Biochem. 103(11):1548-1554.

World Health Organization (1997). Environmental Health Criteria 194: Aluminium. Printed in Finland 97/PLL/11539-Vammala-5000: WHO. pp.1-282. 